\title{
Escuela y lectura: la necesidad de una mirada externa
}

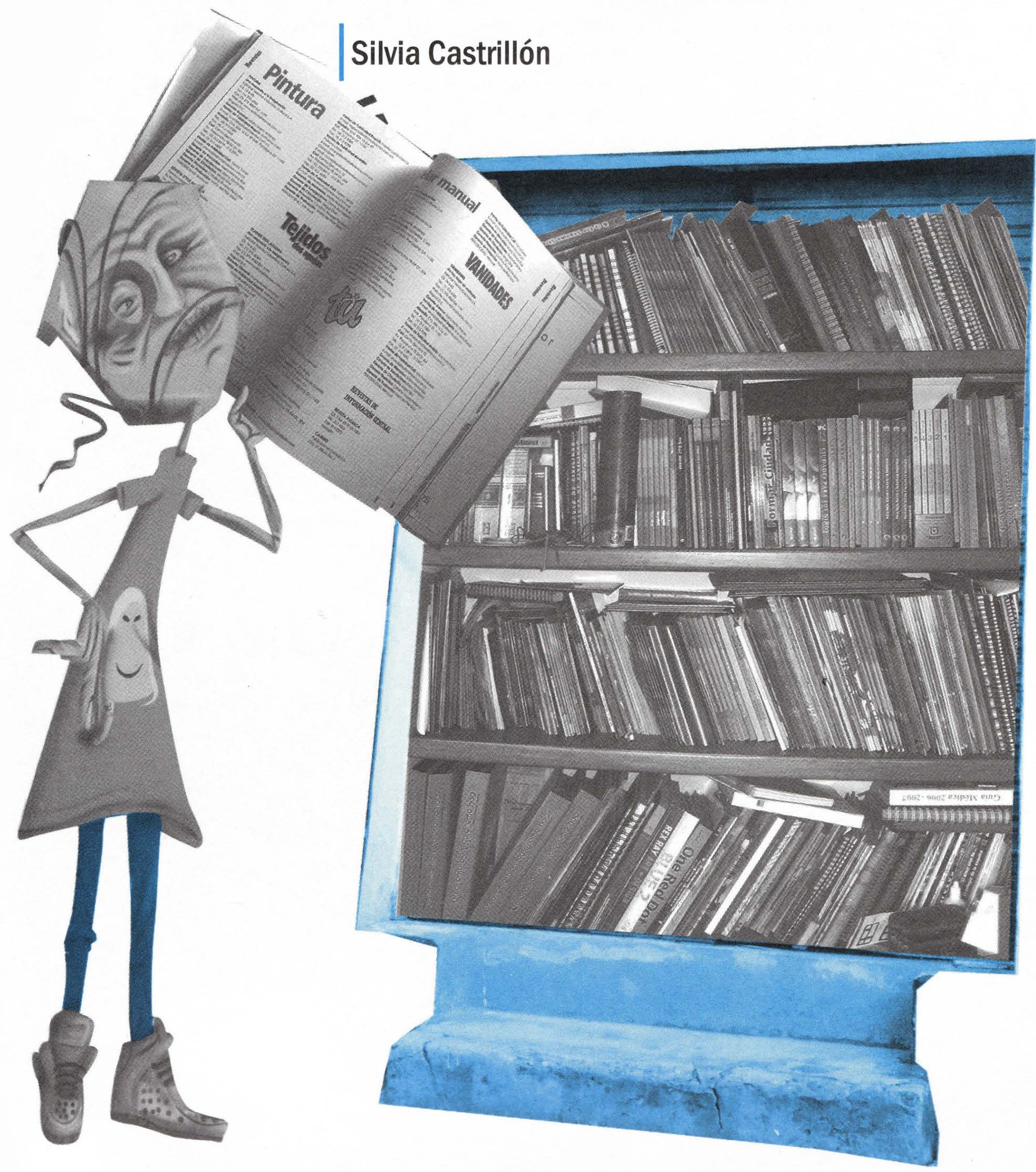


Silvia Castrillón es bibliotecóloga egresada de la Universidad de Antioquia. Ha participado como conferencista en congresos internacionales sobre lectura, literatura infantil y bibliotecas y publicado artículos en diversas publicaciones de España, Francia, Brasil, México, Argentina, Ecuador, Venezuela y Colombia. Autora de los libros: Modelo Flexible para un Sistema de Bibliotecas Escolares. Bogotá: OEA, 1982 y El derecho a leer y a escribir. México: CONACULTA, 2005. Correo electrónico: silvia.castrillon@gmail.com

\section{Resumen}

Las escuelas no cuentan con espacios para una reflexión que les permita tomar distancia frente a sus prácticas pedagógicas, observarlas desde afuera, de tal manera que sea posible analizarlas, ubicarlas en un contexto histórico y local que las determina, y pensar en ellas como procesos que tienen, o deberían tener, consecuencias en el largo plazo. Los maestros conocen bien su práctica pero necesitan someterla a una mirada externa que propicie el distanciamiento o extrañamiento, en términos de la dramaturgia brechtiana. La autora plantea que la democratización de la cultura escrita y del sentido que ella posee en la transformación social, contribuye, a generar condiciones para el pensamiento crítico, para la construcción de sujetos con mejores posibilidades de injerencia en sus realidades y, especialmente, éticamente responsables.

\section{Palabra Clave: lectura, escuela, enseñanza de la lectura y la escritura}

\section{Abstract}

In current conditions schools do not count with instances of study and reflection that allow teachers to see and analyze their own teaching practices from afar, considering them as part of historical and local processes and environments. Teachers have deep knowledge of their practice but they must see them from outside in a Brecth's like appraisal. The author arises a proposal for a democratic writing culture and its sense of social transformation would contribute to building conditions for critical thought and for the education of ethical, responsible individuals who could participate in their own realities in a proper way.

Key words: Reading, schools, teaching reading and writing 


\section{¿Por qué leer? ¿Qué significación tiene la lectura en la sociedad actual? ¿Qué es enseñar a leer y a escribir? ¿Por qué la escuela enseña a leer y a escribir? ¿Por qué y para qué la lectura en un contexto histórico y social?}

Las consideraciones que se presentan a continuación son fruto de una reflexión adelantada con grupos de maestras y maestros de Bogotá. Debido a que se trata de temas complejos y objeto de mayor debate, acompañaré este texto con una bibliografía, que permite mayores profundizaciones. Partimos de una realidad muy negativa: las escuelas no cuentan con espacios para una reflexión que les permita tomar distancia frente a sus prácticas pedagógicas, observarlas desde afuera, de tal manera que sea posible analizarlas, ubicarlas en un contexto histórico y local que las determina, y pensar en ellas como procesos que tienen, o deberían tener, consecuencias en el largo plazo.

Los maestros conocen bien su práctica pero necesitan someterla a una mirada externa que propicie el distanciamiento o extrañamiento, en términos de la dramaturgia brechtiana. Una mirada externa que, además, lleve consigo la teoría -que tampoco los maestros desconocen, pero que, de nuevo, no cuentan con las condiciones que les permita liberarse de las modas que rigen la circulación de la teoría en la academia; apropiarse y tener con ella un contacto más profundo y, sobre todo, utilizarla para someter su práctica a la observación, y entender mejor sus propósitos y el

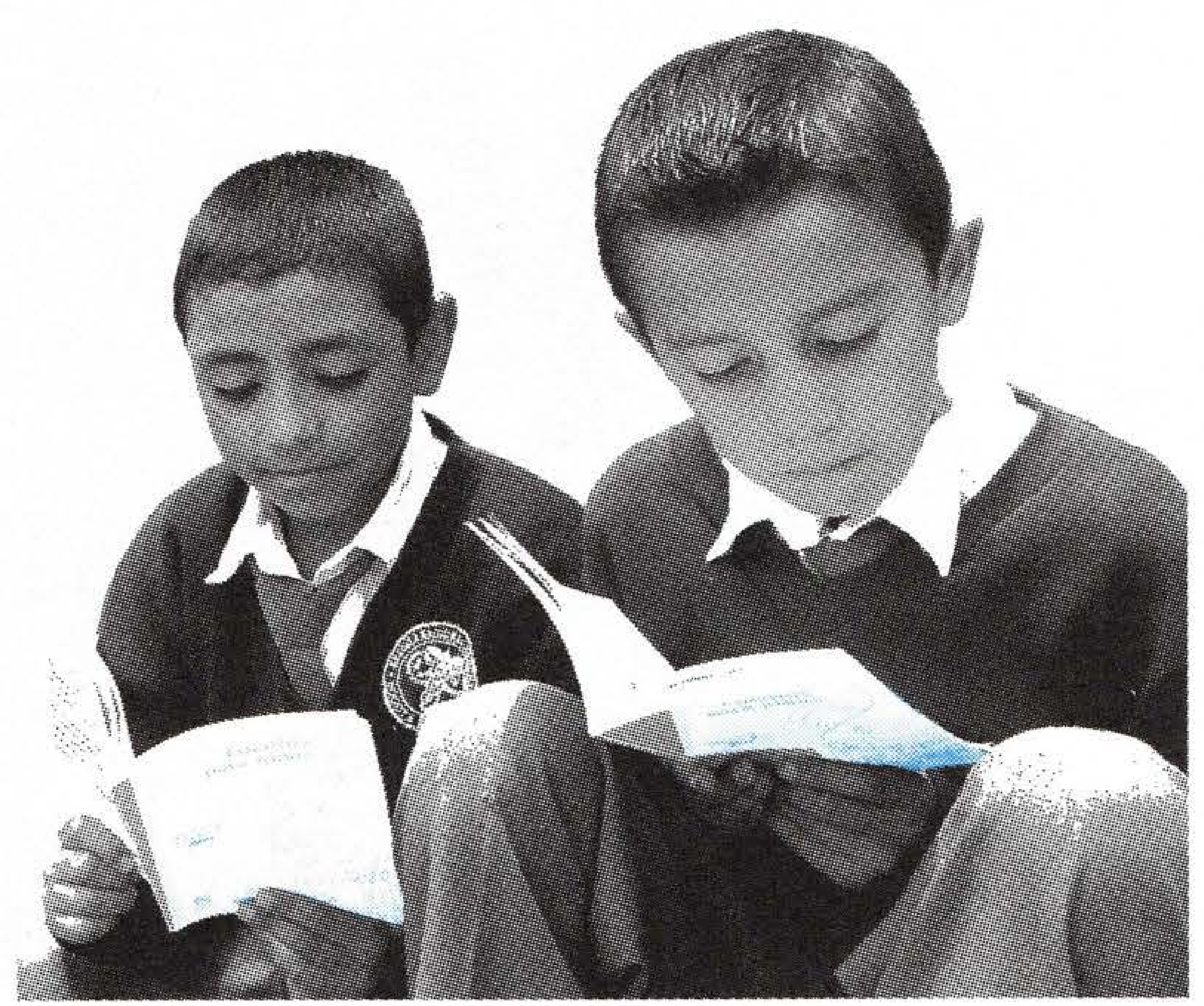

impacto en las transformaciones de las prácticas de lectura que realizan los alumnos y las representaciones que ellos tienen acerca de la cultura escrita. La mayoría de los docentes no se hace preguntas como: ¿Por qué leer? ¿Qué significación tiene la lectura en la sociedad actual? ¿Qué es enseñar a leer a escribir? ¿Por qué la escuela enseña a leer y a escribir? Y otras orientadas a entender mejor el por qué y el para qué de la lectura en un contexto histórico y social.

Nuestra mirada, entonces, es una mirada externa, que si bien reconoce la difícil labor del maestro, no es condescendiente, por el contrario trata de sacudir esquemas, lugares comunes, prejuicios en los que los maestros se instalan fácilmente como mecanismo de defensa a críticas y a exigencias que la sociedad les hace -sin tener muy claro qué es lo que se espera de ellos o sus propias limitaciones en el momento de cumplir con lo que les exige. Lo que se propone, en definitiva, es suscitar los cuestionamientos necesarios para una práctica más consciente. 


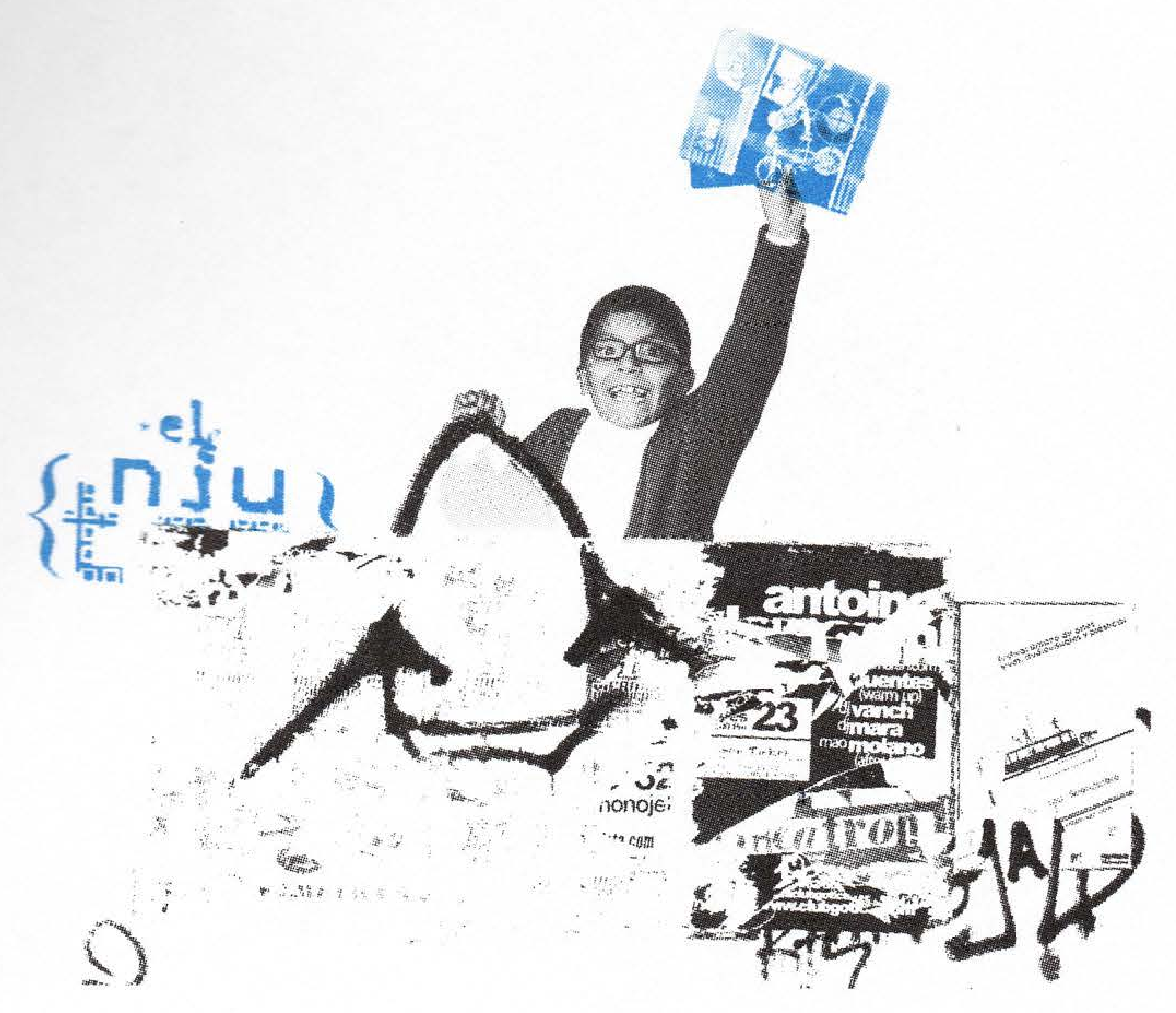

La primera pregunta que nos planteamos se refiere a las motivaciones de los estudiantes para aprender. ¿Qué los mueve? ¿Qué los convoca? ¿Consideran que leer y escribir puede tener algún sentido para sus vidas presentes y futuras?

Las respuestas nos conducen, sin falta y en primer lugar, al tema de las mediciones. Es absolutamente claro que casi la única motivación para ellos es la calificación, la nota. Detrás de esta exigencia existen presiones que provienen del sistema educativo (desempeño de los alumnos en diferentes tipos de pruebas nacionales e internacionales y estímulos que se otorgan a los colegios con base en los resultados) lo que a su vez está presionado por toda la sociedad interesada en resultados utilitaristas inmediatos y pragmáticos. Parecería ser que el único propósito que anima a toda la acción educativa se encierra en las notas, aunque actualmente se presenten de manera camuflada. Los niños, especialmente a partir de segundo grado cuando empiezan a perder otras motivaciones y a entender que lo que se espera de ellos es una calificación, piden la nota, también los padres la exigen, pues de lo contrario asumen que se está perdiendo el tiempo.
Digo casi la única motivación, porque hay momentos que escapan a esta exigencia: cuando se propone la lectura como una práctica lúdica y recreativa. Éste constituye un tema de importantes debates que involucran la significación y el sentido que la sociedad y por ende, la escuela, dan a la lectura. ¿Es posible todavía pensarla como construcción de sentido? ¿Permite una mirada más crítica y menos superficial de la realidad? ¿Tiene la escuela en la sociedad un papel diferente del de formar personas competentes para el trabajo y ciudadanos adaptados y funcionales para la sociedad de consumo? Y entonces, ¿el libro y la lectura dejan de tener sentido en la formación de ciudadanos críticos y seres humanos con una responsabilidad ética frente a los demás? O, ¿definitivamente la escuela fue cooptada por los intereses particulares de la sociedad de consumo como una institución al servicio de lo que el mercado propone como recreación masiva? y ¿el libro y la lectura entran también a formar parte de las industrias culturales que sólo tienen fines lucrativos. 
No se puede negar el placer que puede producir la lectura a una persona que ha superado la dificultad de volverse lector, o mejor, que supera a diario el enfrentamiento con un texto complejo. Sin embargo, el placer como consigna para atraer a la lectura es uno de los lugares comunes más sólidamente asentados en las instituciones en donde la lectura y la escritura es preocupación central: la escuela, pero también, la biblioteca. Y ésta, o es una consigna demagógica que pretende despojar a la lectura de toda dificultad y ofrecer la posibilidad de acceder a ella sin esfuerzo; o, de hecho, se despoja con ella a la lectura del sentido que puede tener en la búsqueda de significación y se la presenta como una mercancía, un bien de consumo, un medio para la evasión, para lo cual la intermediación de la escuela no haría falta.

El profesor Luis Percival Leme Britto, afirmaba recientemente en una conferencia presentada en Río de Janeiro y partiendo de planteamientos de Habermas, que el legado conservador de la contracultura de los años sesenta ha sido el de la subjetividad y el hedonismo, en suma un idealismo reaccionario, una afirmación de la subjetividad absoluta, de la felicidad individual plena que produce una ilusión de libertad. Las principales formas de alineación se dan a través de las industrias de la información y del entretenimiento, entretenimiento que está en contra del arte y que propone el olvido, de acuerdo con palabras del profesor Britto ${ }^{1}$.
El libro y la lectura han sido también colonizadas por esta industria del entretenimiento, y sólo la escuela, podría hacer algo por su rescate, al menos en algunos momentos y circunstancias. Dicho de otra manera: es necesario que la escuela no se haga cómplice de esta colonización y se convierta en un espacio -tal vez el único- de resistencia.

La pregunta que habría que hacerse, es, ¿Cuál es el sentido que la lectura tiene para la sociedad y por qué es necesario que instituciones como la escuela y la biblioteca se ocupen de ella?

Volvamos al tema de la calificación. La evaluación cuantitativa, como única motivación para aprender a leer y escribir (dicho sea de paso, parece ser que es ésta la única motivación para todos los aprendizajes, a menos de que se trate de algunos en donde claramente se puede encontrar un sentido práctico directo para la vida laboral). Ni la escuela, ni la familia ofrecen a los estudiantes pistas claras acerca de la importancia que puede tener para ellos aprender a leer y a escribir y, mucho menos, convertirse en lectores asiduos. No son prácticas corriehtes. ¿Por qué entonces tienen que someterse a semejante esfuerzo, si los estudiantes no encuentran en ella utilidad práctica para su vida futura? Profe, ¿y eso para qué? Es una pregunta frecuente en las aulas. Y la única respuesta que los maestros tienen a mano es el gancho de lo lúdico. 
A nadie le interesa aprender cosas inútiles. Desde que nacemos nuestra necesidad de aprendizaje está ligada a nuestro instinto de supervivencia. Queremos saber lo que nos resulta necesario, y buscamos fuera de nosotros lo que existe como un esbozo o una intuición dentro de nosotros mismos.

Antonio Muñoz Molina ${ }^{2}$

\section{La necesidad}

Entramos acá en la importante reflexión acerca de la 'necesidad' como motivación para el aprendizaje. ¿Es posible que la escuela genere -en contravía de lo que la sociedad propone- una idea de la necesidad que vaya más allá de la supervivencia inmediata y de unas expectativas de consumo de bienes superfluos impuestas por los medios masivos?

Hasta hace poco, la historia, todas las memorias personales, todos los refranes, las fábulas, las parábolas, planteaban lo mismo: la lucha perenne atroz, y ocasionalmente hermosa de vivir con la Necesidad; la Necesidad que es el enigma de la existencia y que, tras la Creación, no ha dejado de aguzar el espíritu humano. La Necesidad produce la tragedia y también la comedia (...). Hoy ha dejado de existir en el espectáculo del sistema. Y, por consiguiente, ya no se comunica ninguna experiencia.... ${ }^{3}$
Dice John Berger, autor inglés, en su libro de ensayos $E l$ tamaño de una bolsa.

Tratar de que la lectura, y específicamente la lectura de la literatura, se constituya en una necesidad, asociándola con otras necesidades del ser humano que han sido suplantadas, sustituidas, por la sociedad de consumo, podría ser tal vez una manera de rescatar para los niños y los jóvenes el sentido de la lectura y la escritura y crear en ellos el deseo de aprenderlas, aún a costa de esfuerzos que se constituirían en retos que estarían dispuestos a superar con gusto.

¿Cuáles podrían ser las necesidades que de una manera u otra se pueden asociar con la lectura, y de manera más concreta, con la lectura de la literatura?

Lo que sigue a continuación es una especulación, compartida con grupos de maestras y maestros, y que parte de reflexiones personales acerca del sentido que puede tener la lectura de la literatura para nosotros en el momento presente. Sin embargo, cuando hablo de nosotros no quiero tener la arrogancia de hablar en nombre de los demás. Parto de que no hay un ser humano esencial con necesidades que se planteen por encima de sus especificidades históricas, étnicas, geográficas, económicas, de clase, de género, etc. Es decir, no estoy segura de que lo que propongo a continuación sean necesidades inherentes a todos los seres humanos, sin importar raza, cultura, edad, sexo, visión del mundo, etc. Pero también considero que, en momentos cuando predomina un discurso sobre

2 Muñoz Molina, Antonio. La disciplina de la imaginación. Bogotá: ASOLECTURA, 2008, Pg. 14

3 Berger, John. Unos pasos hacia una pequeña teoría de lo visible. En: El tamaño de una bolsa. Buenos Aires: Aguilar, Altea, Taurus, Alfaguara, 2004, Pg. 18. 
la diversidad, no estamos dispuestos a reconocer que tal vez nos unen más cosas de las que nos separan. De cualquier manera, presento sólo a título de discusión las reflexiones que siguen. Por otra parte, tampoco creo que la lectura y la escritura constituyan ellas solas las únicas posibilidades de satisfacción de las necesidades que enumero a continuación.

1. Aprender. "Ningún deseo más natural que el deseo de conocer" así comienza el ensayo De la experiencia de Michel de Montaigne. Conocer, aprender, como algo diferente de acumular información, entender, comprender, aprender como posibilidad de apropiación del mundo, como medio para sentirse parte del mundo. La lectura y la escritura, pueden, de alguna manera, contribuir a la satisfacción de esta necesidad que se manifiesta a lo largo de la vida y que ha sido sustituida en la posmodernidad y en las supuestas sociedades de la información y del conocimiento por la acumulación de información que ofrece la sensación de estar enterado, de conocer, de estar al día o por el modelo educativo actual que habla del life-long learning, esto es, aprendizaje de toda la vida, eufemismo - pues señala para toda la vida lo que no es sino un conocimiento que caduca- que impone una visión del mismo asociada a la tecnología y a las competencias para el trabajo.

2. Pensar. Parece absurdo hablar de que pensar pueda constituir una necesidad que haya que promover. Sin embargo, no es exagerado decir que el pensamiento crítico, reflexivo está en decadencia. Los medios masivos imponen un pensamiento hegemónico, una manera única de pensar y de desear. El italiano Giovanni Sartori hablando del retroceso de la civilización y del hombre en su capacidad de pensar dice:

...el regreso de la incapacidad de pensar (el pospensamiento) al pensamiento es todo cuesta arriba. Y este regreso no tendrá lugar si no sabemos defender a ultranza la lectura, el libro, en una palabra, la cultura escrita ${ }^{4}$

Sin embargo, no cualquier libro, ni cualquier práctica de lectura, especialmente, no las prácticas de lectura que se proponen exentas de esfuerzo, de dificultad, conducen de regreso al pensamiento.

3. Belleza. En la película American Beauty, el joven Ricky Fitts, uno de protagonistas, manifiesta su necesidad de captar con su cámara la belleza que el mundo ofrece, y la encuentra en las escenas más insólitas o violentas: la danza de una bolsa de plástico con el viento, una paloma muerta. Acumular belleza para afrontar el mundo parece ser una búsqueda constante entre los adolescentes. El problema es que no saben dónde buscarla y la belleza que la sociedad les ofrece sólo los conduce a la depresión y, en el mejor de los casos, a la pérdida de todo interés 5 .

No sólo la literatura, pero también ella, como arte, ofrece esta" posibilidad de belleza.

4 Sartori, Giovanni. Homo ludens. Buenos Aires: Aguilar, Altea, Taurus, Alfaguara, 1998, Pg. 149.

5 Castrillón, Silvia. La lectura de los clásicos. En: ¿Por qué leer y escribir? Bogotá, D.C.: Secretaría de Cultura Recreación y Deportes, 2007. 
4. Construcción de sí mismo, de la subjetividad. El ser humano necesita narraciones mediante las cuales pueda construir su propia biografía. La subjetividad se expresa y se constituye mediante relatos y testimonios. Numerosos autores lo manifiestan. La ficción que alimenta la niñez y la adolescencia en la sociedad contemporánea, a través especialmente de la televisión, es una ficción exenta de complejidad, es maniquea, estereotipada y no da cuenta de la diversidad ni puede ser el sustento de una subjetividad con un sentido ético, social y político.

Por otra parte, Peter McLaren considera que,

Es necesario comprender la necesidad humana de dar vida a símbolos, lenguaje y gestos. La voz de los estudiantes es un deseo nacido de la biografía personal y del sedimento de la historia; es la necesidad de construirse y afirmarse dentro de un lenguaje capaz de reconstruir la vida privada e investirla de sentido, de validar y confirmar la propia presencia viva en el mundo ${ }^{6}$

La lectura y la escritura, y de manera muy especial la lectura y la escritura de la literatura, no sólo ofrecen alimento para la construcción de la subjetividad y dan la voz para expresarla, sino que permiten entender que esta construcción no se da de manera aislada, sin acogida responsable del Otro.
5. Actuar. La filósofa alemana Hannah Arendt ${ }^{7}$ establece una diferencia entre la labor, el trabajo y la acción, siendo la labor propia de los procesos biológicos para su subsistencia como individuos y como especie, el trabajo propio del ser humano para crear objetos de uso y satisfacción personal, permite condiciones materiales que vayan más allá de la supervivencia inmediata: la producción o adquisición de utensilios, herramientas, artefactos, mercancías, etc., que le mejoran, o le dan la ilusión de mejorar, su existencia y la acción como propia de un ser humano político, ético y con miras a transformar su realidad y que, según Joan-Carles Mèlich "se revela a través del discurso y la palabra". La lectura y la escritura permiten una apropiación y una toma de la palabra con miras a "una lectura crítica del mundo", a la construcción de un lugar más digno para todos y a la expresión de deseos y aspiraciones.

Y de nuevo Peter McLaren: "Es preciso que tanto los docentes como los estudiantes estén en condiciones de situarse a sí mismos como activos agentes sociales, culturales, históricos" y para ello la lectura y la escritura, o mejor dicho una apropiación conciente de esa herramienta e instrumento de poder que constituye la escritura, son necesarias. Y Paulo Freire: "El mundo no es. El mundo está siendo. Mi papel en el mundo, [...] no es sólo el de quien constata lo que ocurre sino también el de quien interviene como sujeto de ocurrencias" y para ello es necesaria "una seria y rigurosa 'lectura del mundo' que no prescinde sino que por el contrario exige una seria y rigurosa lectura de textos" ${ }^{\prime 10}$.

6 McLaren, Peter. Pedagogía, identidad y poder. Rosario, Argentina: Homo Sapiens Ediciones, 2003, Pg. 23.

7 Arendt, Hannah. Labor, trabajo y acción: una conferencia. En: De la historia a la acción. Buenos Aires: Paidos, 2005.

8 McLaren, Peter. Pedagogía crítica, resistencia cultural y la producción del deseo. Buenos Aires: Aique, 1994.

9 Freire, Paulo. Pedagogía de la autonomía. México: Siglo XXI, 1999, Pg. 75.

10Freire, Paulo. Política y educción. México: Siglo XXI, 2001, Pg. 55-56. 


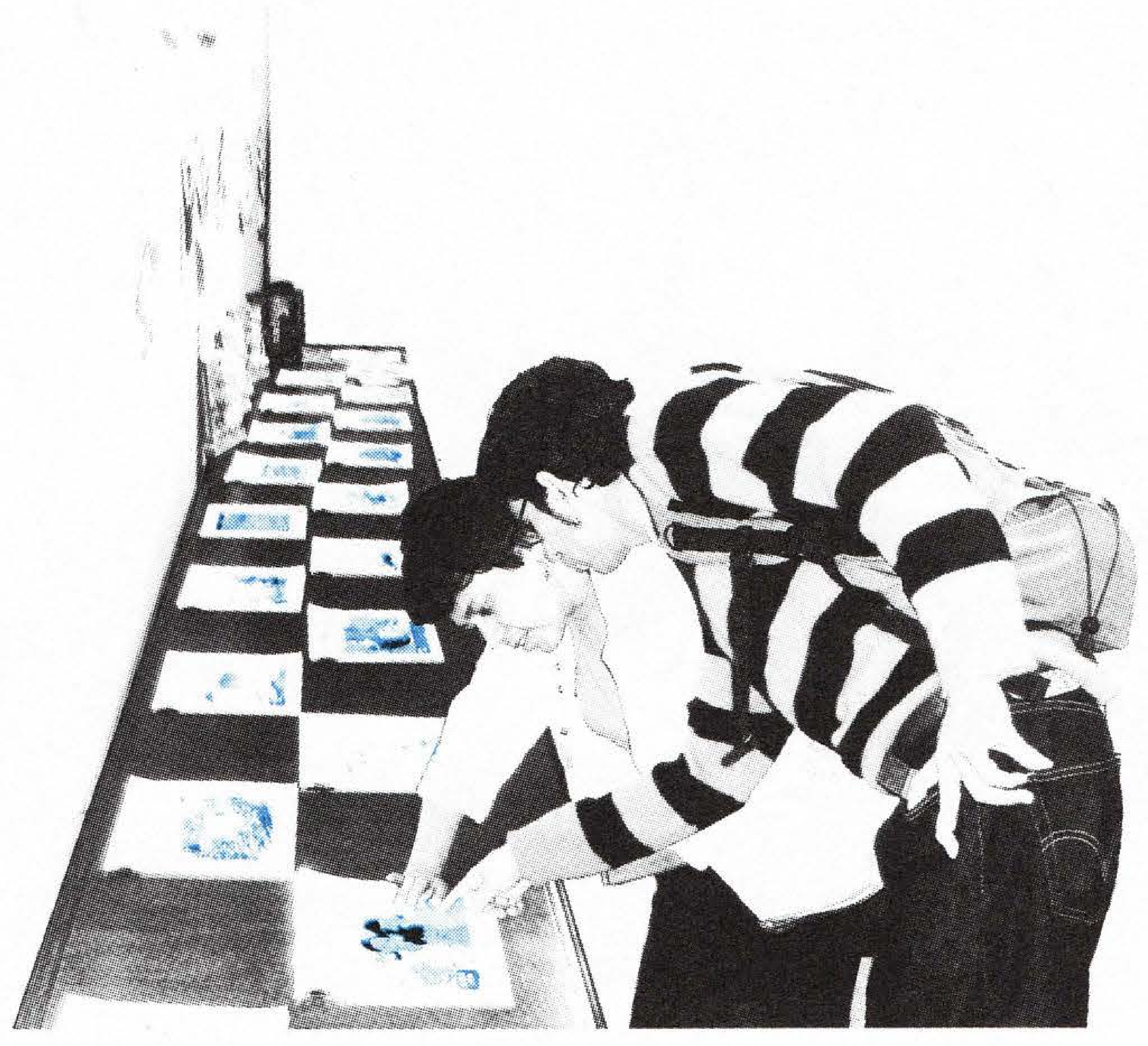

En fin, lo anterior, por supuesto, es apenas un esbozo de las necesidades que se pueden asociar con la lectura. Hay otras:

La lista es larga. Leer responde a una necesidad [...] de reparación, de calificación, de afirmación de sí, de confirmación, de glorificación, de proyección en el futuro, de proyección en el pasado, de sublimación, de exploración, de identificación, de educación, de des-identificación, de des-personalización, de creación o, simplemente y antes que todo, de juego, es decir, de entrada en el dominio del mundo viviente ${ }^{11}$

\section{El papel de la escuela}

Las reflexiones anteriores producen al comienzo de los debates cierta desazón entre los maestros y maestras, pues no vislumbran de qué manera ellos podrían ofrecer las posibilidades para el descubrimiento, por parte de los alumnos, de estas necesidades. Sin embargo, al hacer un análisis de los deseos, las angustias de los adolescentes, las maneras cómo ellos expresan su inconformidad con el mundo, nos empezamos a dar cuenta de que no solamente es posible, sino también necesario -yo diría urgente-, hacerlo y que ellos no sólo son receptivos a propuestas que les señalen un camino emancipador más humano, sino que lo reclaman mediante diferentes tipos de apelaciones que generalmente no sabemos comprender. La reflexión que sigue se orienta hacia cómo la escuela puede crear las condiciones para que el descubrimiento de la necesidad de apropiación por parte de los alumnos, por lo menos de algunos de ellos, sea posible.

\section{Crear las condiciones de posibilidad}

El maestro. La condición de un maestro lector, que se muestre frente a sus alumnos como tal. Todos los maestros leen y escriben pero generalmente lo hacen en función de su trabajo como maestros: presentan informes, revisan textos, llenan formatos, hacen dictados, toman notą en los cursos en donde participan, en ocasiones escriben acerca de sus experiencias, etc. Pero no son éstas las prácticas que podrían motivar en los estudiantes el interés por la lectura y la escritura, pues la mayoría no tiene como proyecto de vida ser maestro. Son otras las prácticas que ofrecerían a sus alumnos ocasión de descubrir la lectura y la escritura como necesidades. Por otra parte, fuera de la escuela, son pocas las ocasiones en las que los adultos se presentan ante los niños y las niñas como usuarios de la cultura escrita. 


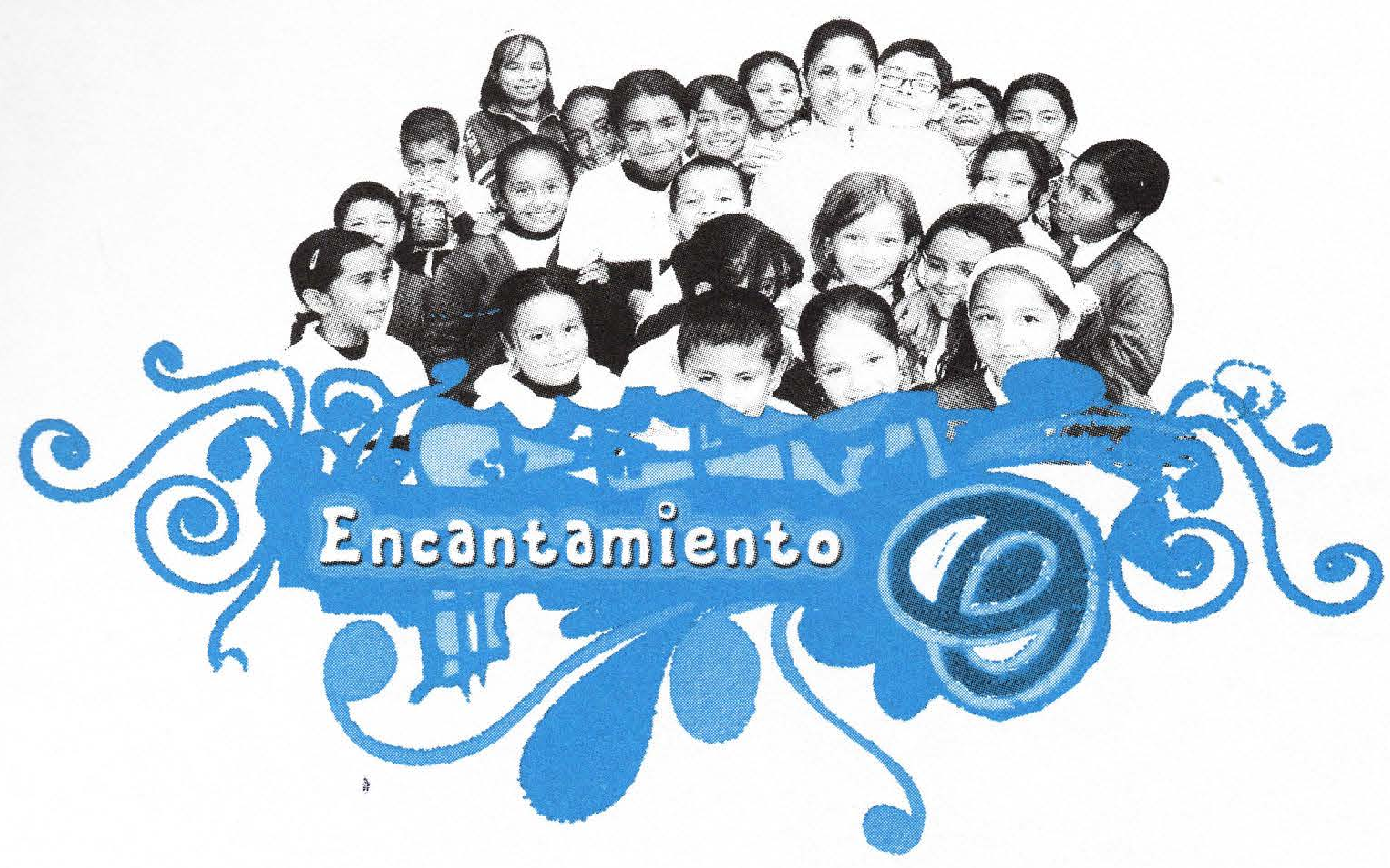

Sin embargo, lo que queremos plantear no es que el maestro sea un ejemplo a seguir de lector, puesto que estaríamos contradiciendo nuestra concepción de lector. Un lector no sigue modelos, no copia. La lectura parte de la duda, de la pregunta, de la ignorancia. La actitud del lector no es la del que todo lo sabe, muy por el contrario es la de quien no se encuentra satisfecho ni complacido con lo que ya sabe y sólo lee para ratificarlo. Es por ello que nos parece que el maestro en lugar de presentarse como ejemplo, que de alguna manera, impone, debe ofrecerse como testimonio. Como texto a leer y a ser interpretado. Las prácticas de lectura y escritura del maestro no deben solamente demostrar su interés por estas actividades, sino dar cuenta de su condición de lector, es decir de una persona que tiene dudas, que no se las sabe todas, que puede cambiar de parecer, que se deja transformar.

$\mathrm{O}$, como dice Michèle Petit hablando de sus maestros: “...tal docente singular tiene la habilidad de haber introducido [a sus alumnos] a una relación con los libros diferente del deber cultural o de la obligación austera, de haber suscitado en ellos el encantamiento, pero también la necesidad de pensar, cuando el o ella elaboraba frente a ellos un pensamiento vivo, en movimiento, en lugar de aplicar un esquema." 12 (El resaltado es mío).

Lo anterior no quiere decir que el papel del maestro sea el de retroceder en el momento de ofrecer opciones, hacer propuestas, plantear su opinión, entrar en debate. No se trata de hacerse a un lado, de no intervenir. Algo que en la actualidad está muy de moda bajo el pretexto de respetar la supuesta autonomía de los estudiantes y su derecho al desarrollo de la libre personalidad, lo cual, en últimas, se convierte en abandono. En nombre del respeto que debo a los alumnos no tengo por qué callarme ${ }^{13}$, dice P. Freire.

12 Petit, Michele. Éloge de la lecture. Paris: Berlin: 2002, Pg. 133.

13 Freire, Paulo. Pedagogía de la autonomía. México: Siglo XXI, 1999, Pg. 69. 
Los buenos libros. Si la escuela quiere que la lectura responda a las necesidades de que hablamos arriba (belleza, pensamiento, ficción, etc.) es necesario que lo haga mediante buenos libros. Mejor dicho, sólo los buenos libros permiten esta respuesta. Libros que movilicen el pensamiento, que permitan verdaderas experiencias estéticas, que ofrezcan posibilidades de constitución de una subjetividad con la complejidad que esto implica y, a su vez, den lugar al reconocimiento de el Otro, en una palabra, libros que una vez se leen se vuelven imprescindibles, libros que no se olvidan, que dejan huella. Sin embargo, la escuela es a veces condescendiente con el argumento que hay que partir de los intereses de los niños, sin hacer una reflexión acerca de la forma en que estos intereses son creados, o mejor, impuestos desde afuera, con fines que no son precisamente los de estimular la experiencia transformadora y el pensamiento crítico. Detrás de la propuesta de que los niños y jóvenes se conviertan en lectores también hay intenciones comerciales que sólo quieren formar consumidores acríticos de libros. El mercado ofrece demasiados libros que reproducen lo que la televisión propone en cuanto a esquemas narrativos, personajes estereotipados, lenguaje despojado de riqueza literaria, y libros de autoayuda que pretenden suplantar al lector en el ejercicio de pensar.
La diversidad de prácticas de lectura. Una tercera condición de posibilidad sería la de multiplicar y diversificar las prácticas de lectura, pero a condición de que estas prácticas se realicen con un sentido asociado a la naturaleza de la lectura, que las prácticas permitan el descubrimiento de la necesidad de la lectura y de la escritura, que estén asociadas con necesidades reales, en una palabra que sean significativas. Este debate se enriquece espacialmente con lo que propone Delia Lerner en su libro Leer y escribir en la escuela, lo real to posible y lo necesario.

Favorecer una verdadera experiencia de lectura. Con frecuencia los maestros se preguntan a sí mismos o a quienes acompañamos procesos como éste iqué puedo hacer con ese libro? O afirman, a continuación de la lectura de un libro de literatura para niños o jóvenes, ese libro está preciso para trabajar determinado tema o valor. Para el maestro el libro no es válido si no ve en él una relación directa con un trabajo práctico en el aula. No se concibe la lectura si no se materializa en algo concreto, que se pueda ver y medir.

La escuela controla la experiencia de múltiples maneras: con el activismo, con el exceso de información y, especialmente, con la nota como meta única de cualquier práctica de lectura y escritura.

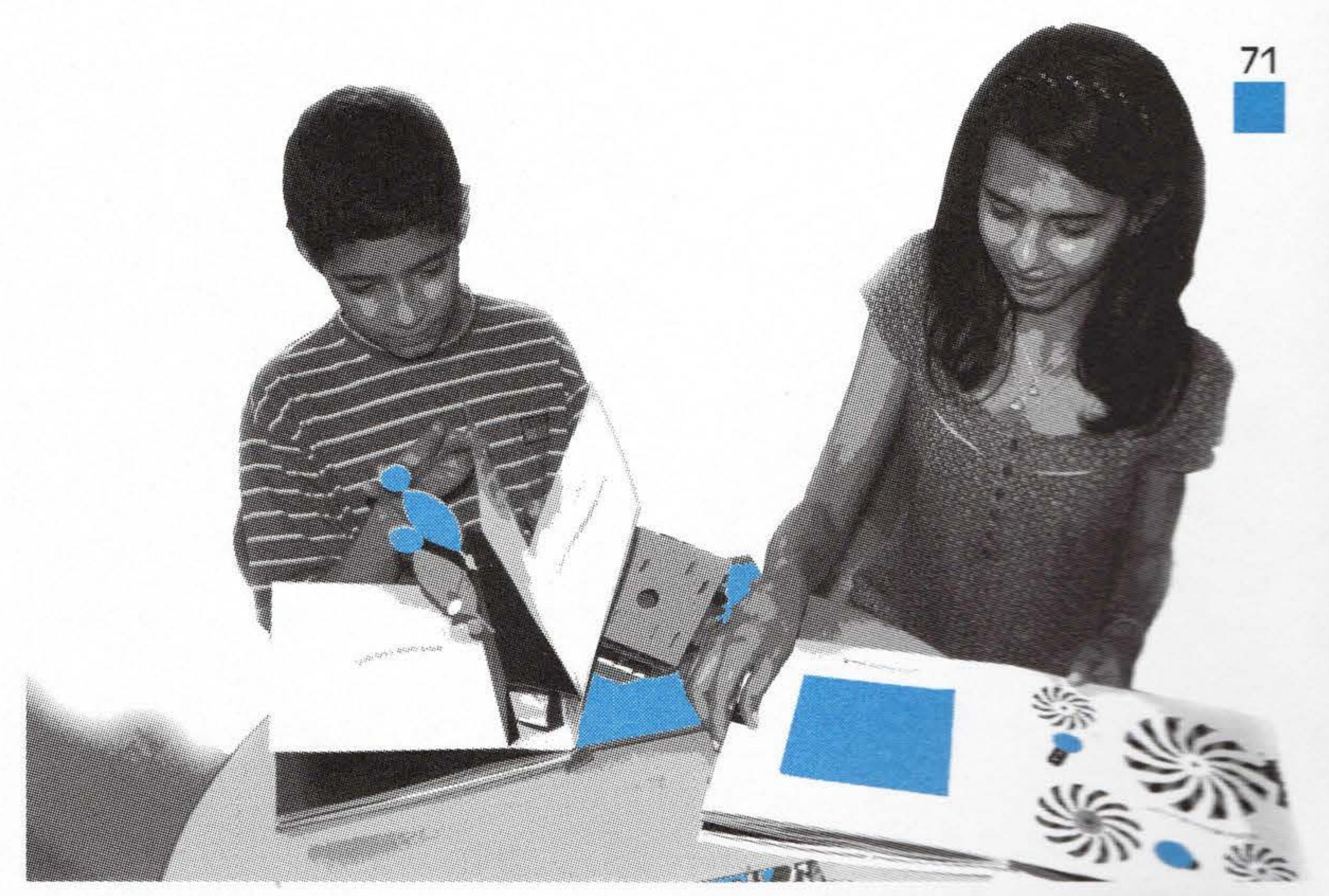


El silencio como condición para la experiencia. George Jean en su libro: Los senderos de la imaginación infanti $1^{14}$ dice que le gustaría escribir una pedagogía del silencio, pero no sobre aquel silencio que precede a una orden. La escuela debería ofrecer el silencio como posibilidad de reflexión, pensamiento, diálogo interior, sin los cuales no es posible una verdadera experiencia, pero no lo hace por dos razones: por la imposibilidad de evaluar esos momentos y porque cree responder a los intereses de los alumnos cuando les ofrece música y ruido estridentes.

Propongo la lectura de Jorge Larrosa, especialmente de su libro: La experiencia de la lectura y de Joan-Carles Mèlich: Filosofía de la finitud para profundizar sobre el tema de la experiencia.

Lo anterior no es más que un punto de partida para reflexiones que la escuela está en mora de emprender con miras a romper con modelos educativos que se imponen con intereses totalizadores y deshumanizantes, o como dice Emilia Ferreiro:

Modelos hegemónicos de comportamientos (individuales y sociales) por parte de los medios masivos de comunicación y de modelos de organización social de un consumismo voraz de objetos, que se convierten en objetos de deseo: automóviles, dispositivos electrónicos, etc., todo, absolutamente TODO, puede convertirse en mercancía, inclusive LAS PERSONAS ${ }^{15}$
Somos por otra parte, conscientes de que la transformación de representaciones, imaginarios y prácticas de lectura y escritura como necesidades para todos los seres humanos, no se dan en el corto plazo, especialmente si pensamos que ya se han venido dando, o ya se han dado, grandes modificaciones sobre el sentido que para la sociedad pueden tener la lectura y la escritura gracias a las propuestas - por no decir a las imposiciones- totalizadoras de la sociedad de consumo que se presentan mediante su principal instrumento de masificación: los medios de comunicación. La escritora argentina Graciela Montes dice,

Da la sensación de que nuestro tiempo... ha perdido su confianza en la lectura, no está muy seguro de para qué sirve $y$, avergonzado por haber dejado caer algo tradicionalmente tan valioso, de a ratos compone elegías sobre ella y de a ratos la disfraza y la hace bailar como a un monito ${ }^{16}$

O, como diría el sociólogo español Enrique Gil Calvo, la lectura pierde el monopolio de la construcción social de la realidad y tampoco se constituye ya en criterio de selección social y de ilustración de las elites ${ }^{17}$.

14 Jean, George. Los senderos de la imaginación infantil. México: Fondo de Cultura Económica, 1990.

15 Notas tomadas por la autora del artículo en la conferencia de Emilia Ferreiro: La alfabetización en perspectiva. presentada en el XXII Congreso Mundial de Lectura. San José de Costa Rica, julio 31, 2008.

16 Montes Graciela. El espacio social de la lectura. En: La educación lectora. Madrid: Fundación Germán Sánchez Ruipérez, 2001.

17 Gil Calvo, Enrique. El destino lector. En: La educación lectora. Madrid: Fundación Germán Sánchez Ruipérez, 2001. 
¿Tiene sentido entonces, ir en contravía de lo que lo que propone la sociedad actual e invertir esfuerzos y recursos en prácticas que ella ya no valoriza y que han perdido significación como manera de entender el mundo y de entendernos a nosotros mismos?

Creo ésta es una falsa pregunta. Lo que habría que preguntarse, a mi modo de ver, es si todavía tiene sentido insistir en la necesidad de entender, de comprender, de pensar, de participar, en la necesidad de actuar -comprendiendo- para transformar. Si es todavía posible imaginar un futuro diferente, más equitativo, menos injusto con la mayoría. Si es posible generar en los niños y las niñas la idea de que aún pueden tener esperanza en su porvenir, pero no en un porvenir que privilegie el éxito individual basado en unas competencias laborales. Si aún es posible generar en ellos una confianza en sí mismos y en los demás, que les permitiría imaginar otras maneras de vivir y de convivir más solidarias, menos violentas, más justas.

No quiero decir con lo anterior que la lectura y la escritura, como prácticas sociales, sean las únicas vías de construcción de sentido y de formas de acción y de transformación, ni que de su apropiación se derivaría un cambio para la vida de la mayoría de las personas. Sólo quisiera plantear que la democratización de la cultura escritura y del sentido que ella tiene en la transformación social, contribuye, a generar condiciones para el pensamiento crítico, para la construcción de sujetos con mejores posibilidades de injerencia en sus realidades y, especialmente, éticamente responsables.

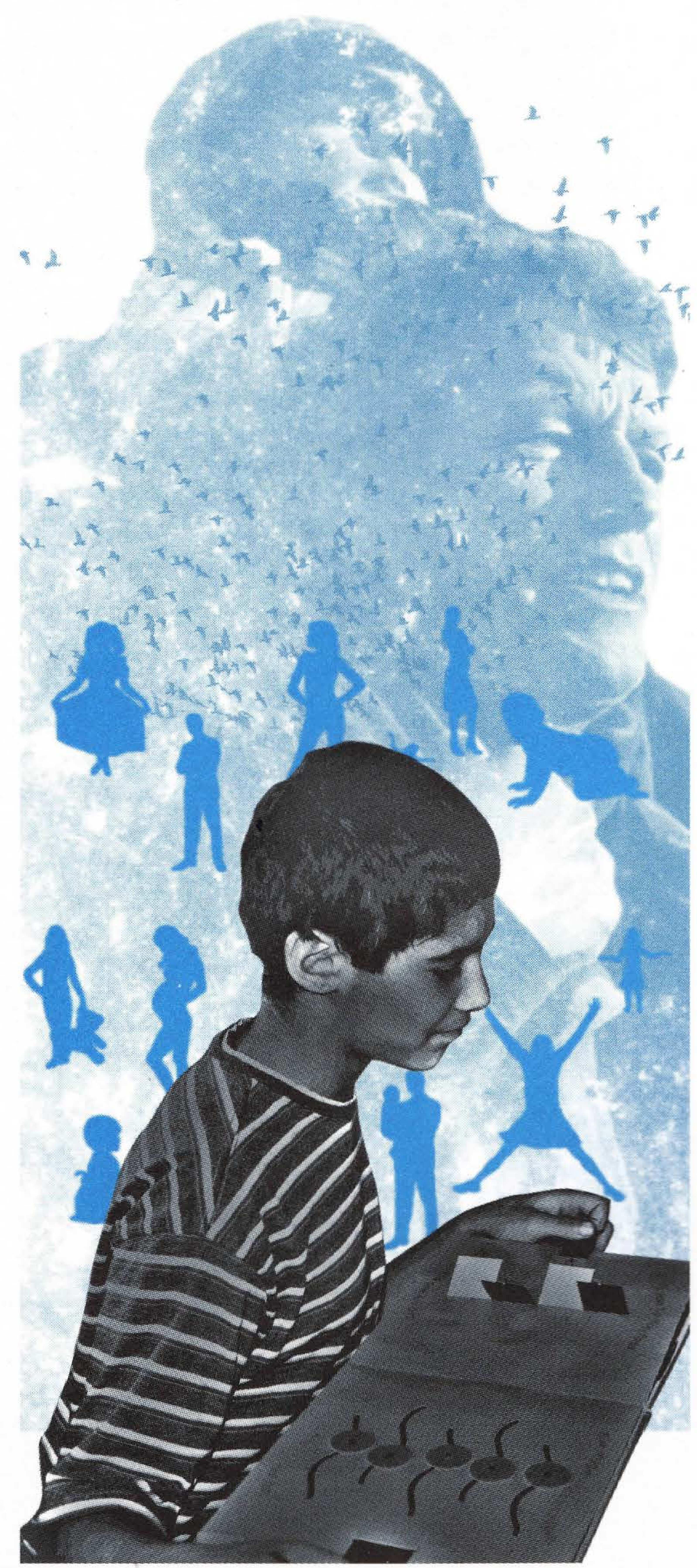




\section{Bibliografía}

Arendt, Hannah. Labor, trabajo y acción: una conferencia. En: De la historia a la acción. Buenos Aires: Paidós, 2005.

Berger, John. Unos pasos hacia una pequeña teoría de lo visible. En: El tamaño de una bolsa. Buenos Aires: Aguilar, Altea, Taurus, Alfaguara, 2004.

Castrillón, Silvia. La lectura de los clásicos. En: ¿Por qué leer y escribir? Bogotá: Secretaría de Cultura Recreación y Deportes, 2007.

Freire, Paulo. Pedagogía de la autonomía. México: Siglo XXI, 1999.

Freire, Paulo. Política y educación. México: Siglo XXI, 2001.

Gil Calvo, Enrique. El destino lector. En: La educación lectora. Madrid: Fundación Germán Sánchez Ruipérez, 2001.

Jean, George. Los senderos de la imaginación infantil. México: Fondo de Cultura Económica, 1990.
Larrosa, Jorge. La experiencia de la lectura. México: Fondo de Cultura Económica, 2003.

McLaren, Peter. Pedagogía crítica, resistencia cultural y la producción del deseo. Buenos Aires: Aique, 1994.

McLaren, Peter. Pedagogía, identidad y poder. Rosario, Argentina: Homo Sapiens Ediciones, 2003.

Mèlich, Joan-Carles. Filosofía de la finitud. Barcelona: Herder, 2002.

Montes, Graciela. El espacio social de la lectura. En: La educación lectora. Madrid: Fundación Germán Sánchez Ruipérez, 2001.

Muñoz Molina, Antonio. La disciplina de la imaginación. Bogotá, D.C.: Asolectura, 2008.

Ouaknin, Marc-Alai. Bibliothérapie. París: Seuil, 1994.

Sartori, Giovanni. Homo ludens. Buenos Aires: Aguilar, Altea, Taurus, Alfaguara, 1998. 